\title{
Eating disorders in university students in Lodz, the role of a family physician
}

\author{
MAŁGORZATA KOZIARSKA-ROŚCISZEWSKA ${ }^{1, A, D, E, ~ G}$, MARIA DOBIELSKA $^{2, A-F}$, \\ ORCID ID: 0000-0002-5438-5837 \\ ORCID ID: 0000-0001-9694-4396 \\ MARZENA OCETEK 2, A, B, D-F, PATRYCJA IWAN ${ }^{3, A, ~ C-F}$, PRAVEEN MALIK ${ }^{4, A, ~ D-F}$, \\ ORCID ID: 0000-0002-3876-292X ORCID ID: 0000-0002-8586-8006 ORCID ID: 0000-0002-8769-6631 \\ ADAM JÓŹWIK ${ }^{5, C-E}$, JACEK RYSZ ${ }^{1, A, G}$ \\ ORCID ID: 0000-0002-3287-7064 ORCID ID: 0000-0002-2757-6443 \\ ${ }^{1}$ Nephrology, Hypertension and Family Medicine Department, Medical University of Lodz, Poland \\ ${ }^{2}$ Students' Scientific Association of Family Medicine, Medical University of Lodz, Poland \\ ${ }^{3}$ Internal Medicine Department, Main-Spessart Clinic, Marktheidenfeld/Lohr, Germany \\ ${ }^{4}$ School of Professional Studies (SPS), Clark University, Lodz, Poland \\ ${ }^{5}$ Faculty of Physics and Applied Informatics, University of Lodz, Poland
}

A - Study Design, B - Data Collection, C - Statistical Analysis, D - Data Interpretation, E - Manuscript Preparation, F- Literature Search, G - Funds Collection

Summary Background. Eating disorders (EDs) seem to be a serious health problem in contemporary Polish society. Family Physicians (FPs) have a vital and pivotal role to play in prevention, diagnosis, treatment and management of EDs.

Objectives. To determine the prevalence of EDs among students in Lodz - one of the biggest university centers in Poland; the main causes and triggers of EDs and the role of an FP.

Material and methods. A voluntary anonymous questionnaire concerning ED prevalence, attitude to ED treatment and potential risk factors, including family relations, was distributed on facebook.com via private groups dedicated only to students from leading universities in Lodz (Poland). 651 answers from students 18-46 year of age were collected. The data was analyzed mainly using the chi-square test with Yates correction.

Results. The research revealed: overall ED prevalence 7.4\%; EDs in females $9.5 \%$ and $2.5 \%$ in males $(p=0.003)$. ED students more often indicated an unhealthy parent-child relationship as a risk factor $(p<0.001) .49 \%$ of students thought that an FP could help with EDs. Conclusions. Family dysfunction, peer opinions and the influence of social media are major factors and triggers leading to EDs. FPs could play an important role, as they are well situated among other health professionals, are highly approachable by the local population and may have a unique insight into a patient's condition. Further education and training of FPs and the revision of appropriate guidelines for the management of patients with EDs are essential.

Key words: general practitioners, anorexia, feeding and eating disorders, students, community medicine, family physicians.

Koziarska-Rościszewska M, Dobielska M, Ocetek M, Iwan P, Malik P, Jóźwik A, Rysz J. Eating disorders in university students in Lodz, the role of a family physician. Fam Med Prim Care Rev 2021; 23(2): 179-184, doi: https://doi.org/10.5114/fmpcr.2021.105920.

\section{Background}

According to the Diagnostic and Statistical Manual of Mental Disorders V (DSM-5 2013): Feeding and EDs are characterized by a persistent disturbance of eating or eating-related behaviors that results in the altered consumption or absorption of food and that significantly impairs physical health or psychosocial functioning. EDs, such as anorexia nervosa (AN) and bulimia nervosa (BN), are complicated health problems that affect both the body and the mind in different age groups, as well as in in young people [1].

The main focus of our study is on AN and BN among university students, as most of the data indicates that the prevalence of EDs in this group may be higher than in the general population.

AN is defined as a restriction of energy intake relative to requirements, leading to significantly low body weight in the context of age, gender, developmental trajectory and physical health. Body weight or shape strongly influences self-evaluation of people, who suffer from AN. Moreover, a patient with AN is unable to recognize how dangerous the current low body weight is [1].
$\mathrm{BN}$ is a recurrent episode of eating an amount of food that is definitely larger than what most individuals would eat in a similar period of time under similar circumstances with a sense of lack of control over eating during the episode. Moreover, recurrent inappropriate compensatory behaviors in order to prevent weight gain, such as self-induced vomiting, misuse of laxatives, diuretics or other medications, fasting or excessive exercise, occur after these episodes. Simultaneously, self-evaluation is unduly influenced by body shape and weight [1].

A variety of data on ED frequency (6.8-40.2\%) among university students has been reported all over the world, all of which indicates a higher incidence in the young then in the general population [2-7]. This indicates that students are a social group which is particularly vulnerable to the occurrence of EDs. Therefore, this topic is relevant and worth researching to find a way to prevent EDs among students and young people in general. It seems that EDs derive from strained family relations; however, studies vary significantly in details [8-11]. The way of providing information about nutrition by parents and the influence of mass media are also important, as these may increase the risk of EDs by four times $[12,13]$. 


\section{Objectives}

We decided to determine the prevalence of EDs among students in Lodz - one of the biggest university centers in Poland - and reveal the main causes and triggers of EDs, as well as to define the role of FPs.

\section{Material and methods}

Our survey was conducted in 2019. We distributed an online anonymous questionnaire on facebook.com via private groups dedicated only to university students in Lodz (Poland). The questionnaire was spread among students (69.6\% females) from various faculties of leading universities in Lodz. Volunteer students completed the questionnaire concerning their studies, attitude to EDs, preferred therapy, previous ED diagnosis and potential trigger factors. Every response was taken into account. Initially, we wanted to collect at least 200 answers. Out of 651 answers received, $49.1 \%$ were from medical students, the rest came from non-medical faculties. The respondents were divided into two groups: experienced EDs directly (EEDD) and non-experienced EDs directly (Non-EEDD). EEDD refers to the students who were either diagnosed with EDs or suspected that they could suffer from an ED or knew someone suffering from an ED. Non-EEDD made up the rest of the study group. Using these categories, we compared the opinions of students representing various levels of experience and knowledge about EDs. We investigated the impact of these features on family physicians' preventive measures and treatment of patients prone to or suffering from mental health issues.

\section{Statistical analysis}

The statistical data analysis consists mainly of an investigation on the dependencies between two qualitative variables. All existing tests that may be applied to these tasks are based on contingency tables. The most frequently used test was the chi-square test with Yates correction. The chi-square test and v-square tests were rarely applied. The data was analyzed using STATISTICA 9.0.

\section{Ethical considerations}

The study was approved by the Medical University of Lodz Bioethics Commission (No. RNN/219/19/KE) on the $9^{\text {th }}$ of March 2019.

\section{Results}

9.5\% (43) of female and $2.5 \%$ (5) of male university students in Lodz declared they had been diagnosed with EDs. EDs were more common among females $(p=0.003)$ (Table 1$)$.

\begin{tabular}{|l|l|l|}
\hline \multicolumn{3}{|c|}{ Table 1. Dependence of ED frequency on gender $(\boldsymbol{p}=\mathbf{0 . 0 0 3})$} \\
\hline & Women & Men \\
\hline No ED diagnosed & $90.5 \%$ & $97.5 \%$ \\
\hline ED diagnosed & $9.5 \%$ & $2.5 \%$ \\
\hline
\end{tabular}

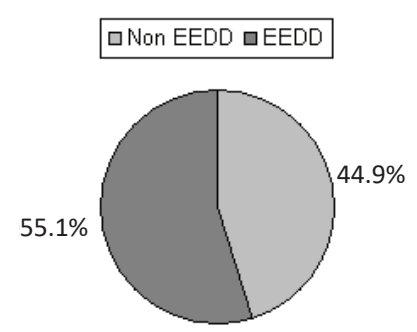

Figure 1. Distribution of respondent's ED experience
$55.1 \%$ (359) of students experienced an ED directly in their lifetime (Figure 1). $59.5 \%$ of these students thought that EDs are stigmatized in society. Non-EEDD students less often (48.6\%) believed that a stigma was associated with $\operatorname{EDs}(p=0.042)$ (Table 2).

\begin{tabular}{|c|c|c|c|c|}
\hline$p=0.042$ & $\begin{array}{l}\text { Stigma? } \\
\text { Yes }\end{array}$ & $\begin{array}{l}\text { Stigma? } \\
\text { No }\end{array}$ & $\begin{array}{l}\text { Don't } \\
\text { know }\end{array}$ & Row sum \\
\hline EEDD & \begin{tabular}{|l|}
210 \\
$(58.5 \%)$
\end{tabular} & \begin{tabular}{|l|}
92 \\
$(25.6 \%)$
\end{tabular} & \begin{tabular}{|l|}
57 \\
$(15.9 \%)$
\end{tabular} & \begin{tabular}{|l|}
359 \\
$(100 \%)$
\end{tabular} \\
\hline Non-EEDD & \begin{tabular}{|l}
142 \\
$(48.6 \%)$
\end{tabular} & \begin{tabular}{|l}
91 \\
$(31.2 \%)$
\end{tabular} & \begin{tabular}{|l}
59 \\
$(20.2 \%)$
\end{tabular} & \begin{tabular}{|l}
292 \\
$(100 \%)$
\end{tabular} \\
\hline Total & \begin{tabular}{|l}
352 \\
$(54.1 \%)$ \\
\end{tabular} & \begin{tabular}{|l}
183 \\
$(28.1 \%)$
\end{tabular} & \begin{tabular}{|l}
116 \\
$(17.8 \%)$
\end{tabular} & \begin{tabular}{|l|}
651 \\
$(100 \%)$
\end{tabular} \\
\hline
\end{tabular}

The vast majority of EEDD students perceived a promotion of a slim figure in the media ( $82.5 \%)$, the destructive influence of social media (80.5\%) and insufficient self-esteem (81.1\%) as ED trigger factors. More than a half of the EEDD students claimed that the risk of EDs is increased by disturbed relationships with peers $(71.6 \%)$ and family (52.9\%). A few students indicated that EDs could be a result of stress (5.6\%), psychological problems ( $5.3 \%$ for mental illnesses and $2.5 \%$ for personality disorders) or improper eating habits (1.4\%) (Table 3 ).

\begin{tabular}{|l|l|l|}
\hline \multicolumn{3}{|l}{ Table 3. ED risk factors by EEDD students } \\
\hline $\begin{array}{l}\text { Frequency of risk factors from among } \\
\text { 359 EEDD cases }\end{array}$ & $\begin{array}{l}\text { Number } \\
\text { of cases }\end{array}$ & $\begin{array}{l}\text { Percent- } \\
\text { age (\%) }\end{array}$ \\
\hline Promotion of a slim figure in media & 296 & 82.5 \\
\hline Low self-esteem & 291 & 81.1 \\
\hline Social media & 289 & 80.5 \\
\hline Peer pressure & 257 & 71.6 \\
\hline $\begin{array}{l}\text { Uncordial and strained relationship with } \\
\text { parents }\end{array}$ & 190 & 52.9 \\
\hline Stress & 20 & 5.6 \\
\hline Coexistence of psychological disorders & 19 & 5.3 \\
\hline Personal predispositions (perfectionism) & 9 & 2.5 \\
\hline $\begin{array}{l}\text { Unhealthy relationship with people from } \\
\text { outside of the family }\end{array}$ & 7 & 1.9 \\
\hline Improper eating habits & 5 & 1.4 \\
\hline
\end{tabular}

Students with strained family relations were diagnosed with EDs three times more often (11.7\%) than students with cordial family relations (3.7\%). The difference in ED diagnosis depending on family relations is significant $(p<0.001)$ (Table 4). EEDD students more often claimed that a strained relationship with parents could cause EDs (52.9\%) in comparison to Non-EEDD students (47.1\%) (Table 5).

Table 4. Diagnosed EDs depending on the relationship with parents $(p<0.001)$

\begin{tabular}{|c|c|c|}
\hline & $\begin{array}{l}\text { Cordial family rela- } \\
\text { tions }\end{array}$ & $\begin{array}{l}\text { Strained family rela- } \\
\text { tions }\end{array}$ \\
\hline No ED diagnosed & $96.3 \%$ & $88.3 \%$ \\
\hline ED diagnosed & $3.7 \%$ & $11.7 \%$ \\
\hline
\end{tabular}

Table 5. Experience of EDs depending on the relationship with parents $(p<0.001)$

\begin{tabular}{|l|l|l|}
\hline & $\begin{array}{l}\text { Cordial family rela- } \\
\text { tions }\end{array}$ & $\begin{array}{l}\text { Strained family rela- } \\
\text { tions }\end{array}$ \\
\hline EEDD & $47.1 \%$ & $52.9 \%$ \\
\hline Non-EEDD & $61.6 \%$ & $38.4 \%$ \\
\hline
\end{tabular}


Students who took into consideration an FP's help in the case of EDs can be divided into two almost equal groups. $49.2 \%$ of all students believed in the competence of an FP, and $50.8 \%$ did not find an FP useful in ED therapy (Table 6).

\begin{tabular}{|l|l|l|}
\hline \multicolumn{3}{|l|}{ Table 6. Belief in the appropriate competences of a family phy- } \\
sician to treat and diagnose EDs among all the study groups \\
\hline & Number of students & Percentage of students \\
\hline Yes & 320 & $49.2 \%$ \\
\hline No & 331 & $50.8 \%$ \\
\hline Total & 651 & $100 \%$ \\
\hline
\end{tabular}

FPs were a bit more often downvoted in the EEDD group. The majority of EEDD students (57.9\%) believed that an FP was not a suitable specialist to help them in the case of EDs. $54.8 \%$ of Non-EEDD students declared that an FP would be an appropriate specialist (Table 7).

\begin{tabular}{|c|c|c|c|}
\hline & Not OK & OK & Don't know \\
\hline Non-EEDD & $43.8 \%$ & $54.8 \%$ & $1.4 \%$ \\
\hline EEDD & $57.9 \%$ & $43.7 \%$ & $1.4 \%$ \\
\hline
\end{tabular}

$28 \%$ of males would have sought help in an FP's office if they had been suffering from EDs, whereas only $20 \%$ of females would do so (Table 8). $76 \%$ of females declared that they would have preferred to see a psychologist in comparison to $65 \%$ of males (Table 9).

\begin{tabular}{|c|c|c|}
\hline & Females & Males \\
\hline Not from a family physician & $79.5 \%$ & $71.7 \%$ \\
\hline From a family physician & $20.5 \%$ & $28.3 \%$ \\
\hline
\end{tabular}

Table 9. Searching for help from a psychologist in the case of EDs depending on gender $(p=0.005)$

\begin{tabular}{|l|l|l|}
\hline & Females & Males \\
\hline Not from psychologist & $24.3 \%$ & $35.4 \%$ \\
\hline From psychologist & $75.7 \%$ & $64.6 \%$ \\
\hline
\end{tabular}

Asking students who had been diagnosed with an ED and had received treatment about forms of ED therapy among three different specialists revealed the students' confusion concerning specialists' competences. $46.9 \%$ of students thought that medicines could be prescribed in the psychologist's office. $72 \%$ thought that psychiatrists could provide psychotherapy. $34.4 \%$ expected dietary counseling from a psychologist (Table 10).

\begin{tabular}{|c|c|c|c|}
\hline & $\begin{array}{l}\text { Psycholo- } \\
\text { gist }\end{array}$ & Psychiatrist & $\begin{array}{l}\text { Family } \\
\text { physician }\end{array}$ \\
\hline Medication & $46.9 \%$ & $72.0 \%$ & $66.7 \%$ \\
\hline $\begin{array}{l}\text { Individual psycho- } \\
\text { therapy }\end{array}$ & $75.0 \%$ & $72.0 \%$ & $44.4 \%$ \\
\hline Group psychotherapy & $0.0 \%$ & $12.0 \%$ & $11.1 \%$ \\
\hline Dietary counsel & $34.4 \%$ & $28.0 \%$ & $44.4 \%$ \\
\hline $\begin{array}{l}\text { Contact to self-help or } \\
\text { self-support group }\end{array}$ & $0.0 \%$ & $8.0 \%$ & $11.1 \%$ \\
\hline Family therapy & $12.5 \%$ & $8.0 \%$ & $11.1 \%$ \\
\hline
\end{tabular}

Other results showed that group psychotherapy was very limited. An FP most commonly gave the patient dietary counseling and referred the patient to a self-help or self-support group and - almost as frequently as psychiatrists - prescribed medication (Table 10).

\section{Discussion}

\section{Differentiated prevalence of ED}

Data on ED prevalence varies depending on a country, population or screening method; however, all studies revealed that EDs occur more often among students in comparison to the general population $[2-4,14-18]$.

A study on the Swiss population (2016) showed that 3.5\% of those examined were diagnosed with an ED at least once in their lifetime (5.3\% females; $1.5 \%$ males) [14]. Keski-Rahkonen and Mustelin (2016, Finland) proved that the prevalence of EDs depending on ethnicity, age and place of residence was 1-4\% for $\mathrm{AN}$ and $1-2 \%$ for $\mathrm{BN}$ among females. The incidence of any ED was only $0.3 \%$ among males. The above results coincide with the Swiss research [15]. According to our research, 9.5\% of females and $2.5 \%$ of males had been diagnosed with an ED. Despite the higher prevalence of EDs in Polish students, in each of the study groups - Swiss, Finnish and Polish - EDs were more frequent in females. American data also indicates that females are more predisposed to EDs. It was revealed that in the USA, $1-2 \%$ of adolescent females presented $A N$, and $1-2 \%$ had $B N$. According to that study, only $0.1-0.3 \%$ of adolescent males had AN, and $0.3-0.5 \%$ had BN [16]. The incidence of an ED was the highest in females aged 15-19 and in males 10-14 years old [17]. Our study is consistent with the above observation showing a higher ED prevalence among female students than male students (Table 1).

According to the National Comorbidity Survey Replication Adolescent Supplement (NCS-A), which examined American teenagers $13-18$ years of age, EDs occurred in $0.3 \%$ for AN and $1.3 \%$ for $\mathrm{BN}$ in females and in $0.3 \%$ for $\mathrm{AN}$ and $0.5 \%$ for $\mathrm{BN}$ in males [18].

There are very few current publications measuring ED prevalence among students in Poland. The latest results (2019) come from a study performed on Warsaw Medical University students (215 participants). The study revealed that $12.1 \%$ of students had been diagnosed with an ED, and $23.26 \%$ were at high risk for EDs [2]. Our study (651 participants) showed that $7.4 \%$ of students had been diagnosed with an ED (Figure 1). Moreover, $36.7 \%$ of all students suspected that they could have had an ED during their lifetime. The differences in ED prevalence between medical students from Warsaw and Lodz may result from the number of students examined, as behavioral patterns and living environments seem to be very similar. However, another study conducted on a large sample may lead to the conclusion that these results could have been underestimated. In an online Healthy Mind Study (HMS) survey, attended by 200,000 students from 180 American and Arab universities, ED prevalence varied from $6.8 \%$ to $40.2 \%$ depending on the country and screening method [3]. A study on medical students from a Romanian university (2015-2016) also showed that as much as $25.7 \%$ of the students suffered from EDs [4]. The faculty probably does not matter in the occurrence of EDs. Our study did not reveal any statistically important differences in ED prevalence between medical and non-medical students.

\section{Experiencing ED}

Our study showed that as much as $55.1 \%$ of all students had direct contact with EDs (Figure 1). It seems that students in Łódż are familiar with mental health issues such as EDs, so they should know where to look for help. However, according to the further examination, the case of EDs is a more complex matter. 
Self-esteem seems to be the lynchpin and a dominant factor that pushes many people prone to EDs away from FPs and, at the same time, thrusting some of them towards psychologists. Stigmatization and fear of discrimination discourage people to talk about EDs and steers them away from even considering seeking help openly [19]. A study carried out among Italian undergraduates revealed that stigmatizing attitudes toward EDs may lead to a reduced search for treatment [20]. In our study, EEDD students more often thought that people with EDs are stigmatized $(59 \%)$ in comparison to Non-EEDD students $(49 \%)$ $(p=0.042)$ (Table 2).

The Italy School of Medicine on Perugia, comparing a group of people suffering from EDs and those without EDs, showed that people with EDs more often experienced psychological violence and sexual abuse in the past [21]. A recent Polish study (160 participants; $80 \%$ females, $18-47$ years of age) tried to establish a correlation between family functioning, EDs and self-esteem [22]. It was proven that EDs among individuals with a negative family environment can be reduced by an individual's positive self-esteem. According to our study, the majority of EEDD students (81.1\%) also suffered from low self-esteem (Table 3).

In our study, we determined that the ubiquitous presence of and instant access to social media seem to have consequential effects on how one perceives oneself. Strained family relations, direct and indirect peer pressure (71.6\%), asserting one's place in immediate surroundings, adhering to slenderness as a paragon of beauty $(82.5 \%)$ and admiration and recognition in the cyber world (80.5\%) are major preoccupations and concerns leading to EDs (Table 3).

The significant influence of mass media on the origin of EDs was proven in a study on Brazilian secondary school students (2017). The study revealed that teenagers affected by mass media had a higher likelihood of presenting risk behaviors for developing EDs in comparison to adolescents, who weren't influenced by mass media (four times higher for males and three times higher for females) [13].

Although it was beyond the scope of this study, it is worth mentioning that, in many cases, EDs may lead to depression [23] and may invoke suicidal thoughts [24, 25]. All of the triggers and factors mentioned above can contribute to this, thus making them significant for our study.

\section{ED as a family disease}

According to our research, students who described the relationship with their parents as strained and tense were diagnosed with EDs three times more often (11.7\%) in comparison to students who considered this relationship as cordial and healthy (3.7\%) (Table 4).

EEDD students more often considered an unhealthy relationship with their parents to be an ED trigger factor $(52.9 \%)$ in comparison to Non-EEDD students (47.1\%) (Table 5). It seems that Non-EEDD students presented lower awareness about the crucial role of the family in developing and treating EDs. To some extent, this may explain why the role of the FP (as a health professional taking care of the family) in the diagnosis and treatment of EDs is devalued.

The origin of EDs in the family has been proven by many scientists, even in Poland. The results vary only in detail. When asking teenagers and their parents, they revealed two main causes of EDs derived from the family: a negative assessment of the female's position in the family and a parental lack of concern for appearance and principles of nutrition. EDs also tends to be developed by people driven by a need for asserting one's autonomy, as slenderness is often perceived as an expression of power and control over one's self [8].

Pilecki et al. revealed that females suffering from EDs described their family relations as deprived of autonomy and intimacy. Simultaneously, the patients' parents tended to achieve uniformity and avoid conflicts while presenting mutual aversion and emotional distance to each other [11]. Our study revealed that, according to $52.9 \%$ of EEDD students, bad interpersonal family relationships (parents-children) are one of the major contributors to the current condition (Table 3). An Italian study on the family psychopathology of ED patients revealed that in families with an AN problem, a feeling of subordination dominated over communication. Families with adolescents diagnosed with BN were, in turn, "chaotic" [26]. Studies carried out in the USA also put emphasis on the matter of family. According to the American study, mothers who internalized media messages regarding thinness as a beauty ideal were most likely to have daughters diagnosed with an ED. Negative feedback from mothers about their daughters' figures and eating patterns significantly increased their daughters' difficulties in maintaining proper eating behaviors [9]. An Australian study on secondary school and university students also proved that receiving negative messages by daughters regarding weight and shape from mothers contributes to disordered eating symptomatology more often than family conflict [10]. Due to the fact that abnormal family functioning triggers EDs, this could be considered a "family disease". FPs often take care of family members for years; therefore, it is reasonable to assume that an experienced specialist should have sufficient insight into the above-mentioned features to notice potential abnormalities. It leads to the conclusion that FPs are able to notice triggering family environments and make a quick diagnosis, as well as undertake proper preventive methods and treatment.

\section{Family physician and ED therapy}

Our study revealed that despite the fact that the role of the family in ED etiopathogenesis seems to be crucial, an FP - taking care of family members - does not seem to be perceived by university students in Lodz as a proper specialist for ED diagnosis and treatment. The research revealed that $49.2 \%$ of students thought that an FP could help them in the case of EDs (Table 6). The insufficient trust of $50.8 \%$ of students may be exaggerated by the fact that some students had left their hometowns and thus did not know any FPs in Lodz. If these students visited their previous FP, the FP would likely notice an altered mood or appearance.

As students' family members were also patients of the same FP, many students may be reluctant and full of doubts as to what theirs FP's response would be. However, it seems that a new FP may also be a possible chance to receive therapy.

The differences associated with gender are significant. Males were more trustful of FPs (Table 8), whereas females would prefer to see a psychologist in the case of an ED (Table 9). This might be caused by males being embarrassed about asking for help concerning mental health issues, which is rooted in society. For males, an FP may be a more socially acceptable specialist.

The majority of EEDD students (57.9\%) believed that an FP was an unsuitable specialist to help them in the case of EDs. Interestingly, $54.8 \%$ of Non-EEDD students declared that the FP would be an appropriate specialist (Table 7). It seems that having experience with EDs raises the awareness of the family role in the origin of EDs, but it underestimates the FP's role in therapy. These results need further investigation. This probably indicates that there is a need to provide some clarification and awareness to the public regarding the role of FPs. FPs should not only diagnose EDs and refer a patient to a mental health specialists, they may also actively seek out patients at risk of EDs and provide proper management at the earliest possible stage.

There is a small number of studies regarding the quality of FPs' help concerning EDs. Canadian scientists carried out a study on a group of highly-educated Caucasian women with EDs [27]. This research, considering a similar population, revealed similar results as ours: $40 \%$ of females reported an extremely positive experience with FPs in their ED treatment, and $70 \%$ of them admitted that the FP was supportive. However, they did not believe that the FP was able to help them. Lack of knowledge 
about ED therapy methods seems to be the biggest problem, though some studies have established the importance of an FP in ED treatment. Australian scientists emphasized a large treatment gap in healthcare for people with EDs. They ascertained that being asked about a person's mental health by an FP was the most effective way to receive treatment from a mental health specialist [28]. Israeli scientists indicated that an FP decides about hospitalization, referral or continuation of therapy; therefore, they can create a therapeutic liaison. An FP may be seen as a core team member or even a multi-disciplinary team coordinator [29].

\section{Treatment and therapy}

Various specialists deal with the treatment of patients with EDs. It is worth emphasizing the special role of an FP, who has many therapeutic options. Early diagnosis, which is associated with better treatment results, is particularly important [30]. We compared the individual frequency of using different forms of therapy, and the data emphasized that psychotherapy in the treatment of EDs had the greatest value [31]. Our study showed that psychotherapy is the most commonly used method by psychologists, while patients usually receive pharmacotherapy from doctors (psychiatrist and FPs) (Table 6). The special role of an FP deserves to be emphasized as a health-professional taking care of the patient and his family for years [29]. It is worth using this role to create therapeutic cooperation and support with a professional team. In addition, the role of psychologists and psychiatrists is often confused in society. Patients do not know what their competencies are nor what the difference is (Table 10). An FP should be the first person the patient refers to in order to receive proper treatment. An FP is also able to coordinate the entire team of specialists involved in a patient's care [30].

There is also the important problem of stigmatization of people with mental illnesses (including EDs) by society. As a result, many patients do not decide on starting treatment through specialists such as a psychologist or psychiatrist. Cooperation with the patient and his environment (family), the ability to refer the patient to appropriate specialists and coordination of the entire treatment process are just some of the features that an FP has. It is worth emphasizing the FP's role, especially since some research shows that only $36 \%$ of people with EDs find FPs to be important in the treatment process [32]. On the other hand, some studies show that FPs do not identify all patients with EDs, so the further education and training of FPs and the creation of guidelines in ED management seem to be important [29].

\section{Conclusions}

1. The prevalence of ED among university students in Lodz (Poland) is significant and amounts to $9.5 \%$ for females and $2.5 \%$ for males.

2. Females appear to be more prone to EDs $(p=0.003)$

3. Family dysfunction, the opinions of peers and the influence of social media are major factors and triggers leading to EDs.

4. Students who had strained family relations were much more often diagnosed with an ED.

5. $49 \%$ of university students thought that an FP could help them with EDs.

6. It is necessary for FPs to proactively seek out patients at high risk of EDs, offer them proper management and increase their knowledge and awareness to help with their treatment process.

7. FPs can play a crucial role, as they are well situated among other health professionals and are highly approachable by the local population.

8. Further education and training of FPs and the revision of appropriate guidelines for the management of patients with EDs are essential.

Source of funding: This work was funded from the authors' own resources.

Conflicts of interest: The authors declare no conflicts of interest.

\section{References}

1. American Psychiatric Association. Diagnostic and Statistical Manual of Mental Disorders 5th ed. Arlington (VA): American Psychiatric Association; 2013: 329-355.

2. Herman M, Mikołap K, Szczepanik K. Assessment of the prevalence of eating disorders amongst students of the medical university of Warsaw and their impact on learning outcomes. 6th Lublin International Medical Congress for Students and Young Doctors; 2019.

3. Fitzsimmons-Craft EE, Karam AM, Monterubio GE, et al. Screening for eating disorders on college campuses: a review of the recent literature. Curr Psychiatry Rep 2019; 21(10): 101, doi: 10.1007/s11920-019-1093-1.

4. Brumboiu MI, Cazacu I, Zunquin G, et al. Nutritional status and eating disorders among medical students from the Cluj-Napoca University Centre. Med Pharm Reports 2018; 91(4): 414-421.

5. Lipson SK, Megan Jones J, Barr Taylor C, et al. Understanding and promoting treatment-seeking for eating disorders and body image concerns on college campuses through online screening, prevention and intervention. Eat Behav 2017; 25: 68-73.

6. Lipson SK, Sonneville KR. Eating disorder symptoms among undergraduate and graduate students at 12 U.S. colleges and universities. Eat Behav 2017; 24: 81-88.

7. Kronfol Z, Khalifa B, Khoury B, et al. Selected psychiatric problems among college students in two Arab countries: comparison with the USA. BMC Psychiatry 2018; 18(1): 1-9.

8. Pilecki M W, Sałapa K, Józefik B. Socio-cultural context of eating disorders in Poland. J Eat Disord 2016; 4: 11.

9. Cooley E, Toray T, Wang MC, et al. Maternal effects on daughters' eating pathology and body image. Eat Behav 2008; 9(1): 52-61.

10. Hanna AC, Bond MJ. Relationships between family conflict, perceived maternal verbal messages, and daughters' disturbed eating symptomatology. Appetite 2006; 47(2): 205-211.

11. Pilecki MW, Kościelniak M, Józefik $B$. The perception of relations in the family of origin of patients with eating disorders and the perception of relations in families of origin of their parents. Psychiatr Pol 2015; 49(4): 731-746.

12. Oliveira S, Marta-Simões J, Ferreira C. Early parental eating messages and disordered eating: the role of body shame and inflexible eating. J Psychol 2019; 153(6): 615-627.

13. Uchôa FNM, Uchôa NM, Daniele TM da C, et al. Influence of the mass media and body dissatisfaction on the risk in adolescents of developing eating disorders. Int J Environ Res Public Health 2019; 16(9): 1508, doi: 10.3390/ijerph16091508.

14. Mohler-Kuo M, Schnyder U, Dermota P, et al. The prevalence correlates, and help-seeking of eating disorders in Switzerland. Psychol Med 2016; 46(13): 2749-2758.

15. Keski-Rahkonen A, Mustelin L. Epidemiology of eating disorders in Europe: prevalence, incidence, comorbidity, course, consequences, and risk factors. Curr Opin Psychiatry 2016; 29(6): 340-345.

16. Herpertz-Dahlmann B. Adolescent eating disorders: update on definitions, symptomatology, epidemiology, and comorbidity. Child Adolesc Psychiatr Clin N Am 2015; 24(1): 177-196. 
17. Micali N, Hagberg KW, Petersen I, et al. The incidence of eating disorders in the UK in 2000-2009: findings from the general practice research database. BMJ Open 2013; 3(5): 3-10.

18. Swanson SA, Crow SJ, Le Grange D, et al. Prevalence and correlates of eating disorders in adolescents: results from the national comorbidity survey replication adolescent supplement. Arch Gen Psychiatry 2011; 68(7): 714-723.

19. Griffiths S, Mitchison D, Murray SB, et al. How might eating disorders stigmatization worsen eating disorders symptom severity? Evaluation of a stigma internalization model. Int J Eat Disord 2018; 51: 1010-1014.

20. Caslini M, Crocamo C, Dakanalis A, et al. Stigmatizing attitudes and beliefs about anorexia and bulimia nervosa among Italian undergraduates. Journal of Nervous and Mental Disease 2016; 204(12): 916-924.

21. Brustenghi F, Mezzetti FAF, Di Sarno C, et al. Eating disorders: the role of childhood trauma and the emotion dysregulation. Psychiatr Danub 2019; 31(Suppl. 3): 509-511.

22. Kroplewski Z, Szcześniak M, Furmańska J, et al. Assessment of family functioning and eating disorders-the mediating role of selfesteem. Front Psychol 2019; 10: 921.

23. Goel NJ, Sadeh-Sharvit S, Trockel M, et al. Depression and anxiety mediate the relationship between insomnia and eating disorders in college women. J Am Coll Health 2020; 23: 1-6, doi: 10.1080/07448481.2019.1710152

24. Smith AR, Zuromski KL, Dodd DR. Eating disorders and suicidality: what we know, what we don't know, and suggestions for future research. Curr Opin Psychol 2018; 22: 63-67.

25. Goel NJ, Sadeh-Sharvit S, Flatt RE, et al. Correlates of suicidal ideation in college women with eating disorders. Int J Eat Disord 2018; 51: 579-584.

26. Cerniglia L, Cimino S, Tafà M, et al. Family profiles in eating disorders: family functioning and psychopathology. Psychol Res Behav Manag 2017; 10: 305-312.

27. Lazare K, Mehak A, Telner D. Exploring the primary care experiences of adult patients with eating disorders: a qualitative analysis, Eat Disord 2019; 18: 1-16, doi: 10.1080/10640266.2019.1605778.

28. Hay P, Ghabrial B, Mannan H, et al. General practitioner and mental healthcare use in a community sample of people with diagnostic threshold symptoms of bulimia nervosa, binge-eating disorder, and other eating disorders. Int J Eat Disord 2020; 53: 61-68.

29. Sayag S, Latzer Y. The role of the family physician in eating disorders. Int J Adolesc Med Health 2011; 14: 261-267.

30. Pritts SD, Susman J. Diagnosis of eating disorders in primary care. Am Fam Physician 2003; 67(2): 297-304.

31. Herpertz S, Hagenah U, Vocks S, et al. The diagnosis and treatment of eating disorders. Dtsch Arztebl Int 2011; 108(40): 678-685.

32. Zeeuws D, Cocquereaux K, Santermans L. Patient's and general practitioner's perspectives regarding disturbed eating. Psychiatr Danub 2019; 31(3): 416-417.

Tables: 10

Figures: 1

References: 32

Received: 20.07.2020

Reviewed: 31.07 .2020

Accepted: 23.12 .2020

Address for correspondence:

Maria Dobielska, MD

ul. 28-ego Pułku Strzelców Kaniowskich 6/10 m. 55

90-750 Łódź

Polska

Tel.: +48 532 441-422

E-mail: mariadobielska@gmail.com 